\title{
Metatarsal Bone
}

National Cancer Institute

\section{Source}

National Cancer Institute. Metatarsal Bone. NCI Thesaurus. Code C12752.

A bone belonging to the middle part of the foot located between toes and ankle. There are 5 metatarsal bones and they are numbered from the medial side. 